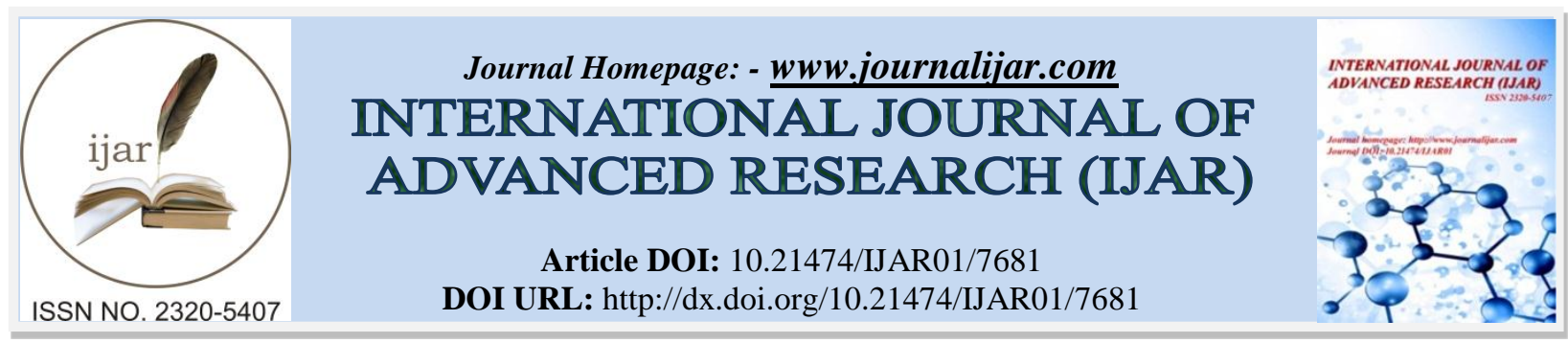

RESEARCH ARTICLE

\title{
EFFECT OF APPLICATION OF CABBAGE LEAVES ON BREAST ENGORGEMENT AMONG POSTNATAL WOMEN- A PILOT STUDY.
}

\section{Ms. Angelina Makwana ${ }^{1}$ and Ms. Anjali Tiwari ${ }^{2}$.}

1. M.Sc Nursing, Manikaka Topawala Institute of Nursing, CHARUSAT, Gujarat- 388421, India.

2. Assistant Professor and HOD, Dept. of Obstetrics \& Gynaecological Nursing, Manikaka Topawala Institute of Nursing, CHARUSAT, Gujarat- 388421, India.

\section{Manuscript Info}

Manuscript History

Received: 06 July 2018

Final Accepted: 08 August 2018

Published: September 2018

Keywords:-

cabbage leaves, breast engorgement, postnatal women.

\begin{abstract}
Introduction and background: During immediate postpartum period there is sudden rise in the production of breast milk. Poor newborn breastfeeding or congestion or obstruction of the breastmilk outflow can give rise to a breast complication called breast engorgement which is commonly found in $2^{\text {nd }}$ and $3^{\text {rd }}$ postpartum day. This study was conducted to evaluate the effect of application of cabbage leaves on breast engorgement among postnatal women. Methodology: The research approach used was quantitative approach. Quasi experimental, Pretest posttest control group design was used. The study was conducted in Arushi Hospital, Petlad and Navjivan hospital, Petlad. 10 postnatal women were conveniently selected (experimental group (5) and control group (5)). The tool of data collection included a Biodemographic Performa, self-developed breast engorgement severity rating scale and Numerical pain rating scale. Pre-treatment assessment for breast- engorgement was done for both experimental and control group. Experimental group was provided with the treatment of application of chilled cabbage leaves 2 times in a day for 3 consecutive days with assessment of breast engorgement after each day whereas control group were not provided with any treatment with assessment daily till 3 days. Results: The data was analyze using descriptive and inferential statistics. The study result showed that there was reduction in mean score of pain from before (6.2) to after (1.0) application of cabbage leaves. In breast engorgement severity rating scale the result showed reduction in all the parameters from pre-treatment mean score to post- treatment mean score which was redness (before 2.4, after 0.2), warmth (before 2.4, after 0.4), hardness (before 2.4, after 0.6), swelling (before 2.2, after 0), lactation (before 1.6, after 0.2). Conclusion: Hence, the study concluded that there exists a huge impact of cabbage leaves on relieving breast engorgement. There is significant reduction in pain and severity of breast engorgement among postnatal women after the application of cabbage leaves. Hence, cabbage leaves can be used as a home-based measure to relieve breast engorgement.
\end{abstract}

Copy Right, IJAR, 2018,. All rights reserved. 


\section{Introduction:-}

During immediate postpartum period there is sudden rise in the production of breast milk. Poor newborn breastfeeding or congestion or obstruction of the breastmilk outflow can give rise to a breast complication called breast engorgement which is commonly found in $2^{\text {nd }}$ and $3^{\text {rd }}$ postpartum day and a common reason cause mother to stop breast feeding sooner than they planned.

According to census 2011 the total female population was $28,948,432 .{ }^{1}$ As per the world bank MMR of India is 174 and of Gujarat is 85 by $2015-2016 .{ }^{2}$ According to international institute for population sciences breast engorgement occurs in 72 to 85 percentages of post-natal women. Among every 10 women, 6 women suffer with breast engorgement. ${ }^{3}$

The factors which causes the breast engorgement are providing other feeds before starting breast feeding, bottle feeding, incomplete emptying of the breast, delay in initiation of breast feeding, long interval between two feeding, etc.

For the successful long-term lactation, it is important to adequately manage the condition. To relieve the discomfort caused bythe engorged breast is the goal of treatment of breast engorgement. There are various Pharmacological and non-pharmacological methods are available to control breast engorgement like expression of breast milk, using of breast Pump, binder, nipple shield, hot and cold application which are costly or may cause discomfort to women.

The common cabbage (Brassica capitata) contains a chemical called sinigrin (allylisothiocyanate). This chemical absorbed through the mother skin and then reduces oedema and increases milk flow. And Cabbage also has antibiotic and anti-irritant properties which improves the blood flow in and out of the area which allows the body to reabsorb the fluid that trapped in the breasts.

\section{Material And Methods:-}

The research approach used was quantitative approach. Quasi experimental, Pretest post-test control group design was used. The study was conducted in Arushi Hospital, Petlad and Navjivan hospital, Petlad. 10 postnatal women were selected (experimental group (5) and control group (5)) using convenient non-probability sampling technique. The tool used for gathering data included

1. Bio-demographic Performa

2. Self-developed and validated Breast engorgement severity rating scale

3. Numerical pain rating scale

Pre-treatment assessment for breast- engorgement done for both experimental and control group. Experimental group was provided with the treatment of application of chilled cabbage leaves 2 times in a day for 3 consecutive day with assessment of breast engorgement after each day whereas control group were not provided with any treatment with assessment daily till 3 days.

\section{Result:-}

The data was analyzed with the use of descriptive and inferential statistics. The study result showed that there was reduction in mean score of pain from before (6.2) to after (1.0) application of cabbage leaves. In breast engorgement severity rating scale, the result showed reduction in all the parameters from pre-treatment mean score to posttreatment mean score which was redness (before 2.4, after 0.2), warmth (before 2.4, after 0.4), hardness (before 2.4, after 0.6), swelling (before 2.2, after 0), lactation (before 1.6, after 0.2). this shows there is a huge impact of cabbage leaves on breast engorgement.

Table 1:-Comparison for mean score of pain in breast engorgement between before and after all 3 days in experimental group

\begin{tabular}{|l|l|l|l|l|}
\hline & Before treatment & After 1 day & After 2 days & After 3 days \\
\hline Pain & 6.2 & 4.6 & 3.0 & 1.0 \\
\hline
\end{tabular}

The above table showed that there was reduction in pain after the application of cabbage leaves among postnatal women of experimental group from before treatment (6.2) to after 3 days (1.0). 
Table 2:-Comparison for mean score of breast engorgement parameters between before and after all 3 days in experimental group

\begin{tabular}{|l|c|c|c|c|}
\hline \multicolumn{1}{|c|}{ Parameters } & Before treatment & After 1 day & After 2 days & After 3 days \\
\hline Redness & 2.4 & 2.0 & 1.4 & 0.2 \\
\hline Warmth & 2.4 & 2.0 & 1.4 & 0.4 \\
\hline Hardness & 2.4 & 1.8 & 1.4 & 0.6 \\
\hline Swelling & 2.2 & 1.6 & 0.8 & 0 \\
\hline Lactation & 1.6 & 1.0 & 0.8 & 0.2 \\
\hline
\end{tabular}

The above table showed that reduction in all the parameters of breast engorgement scale from before treatment to till 3 days.

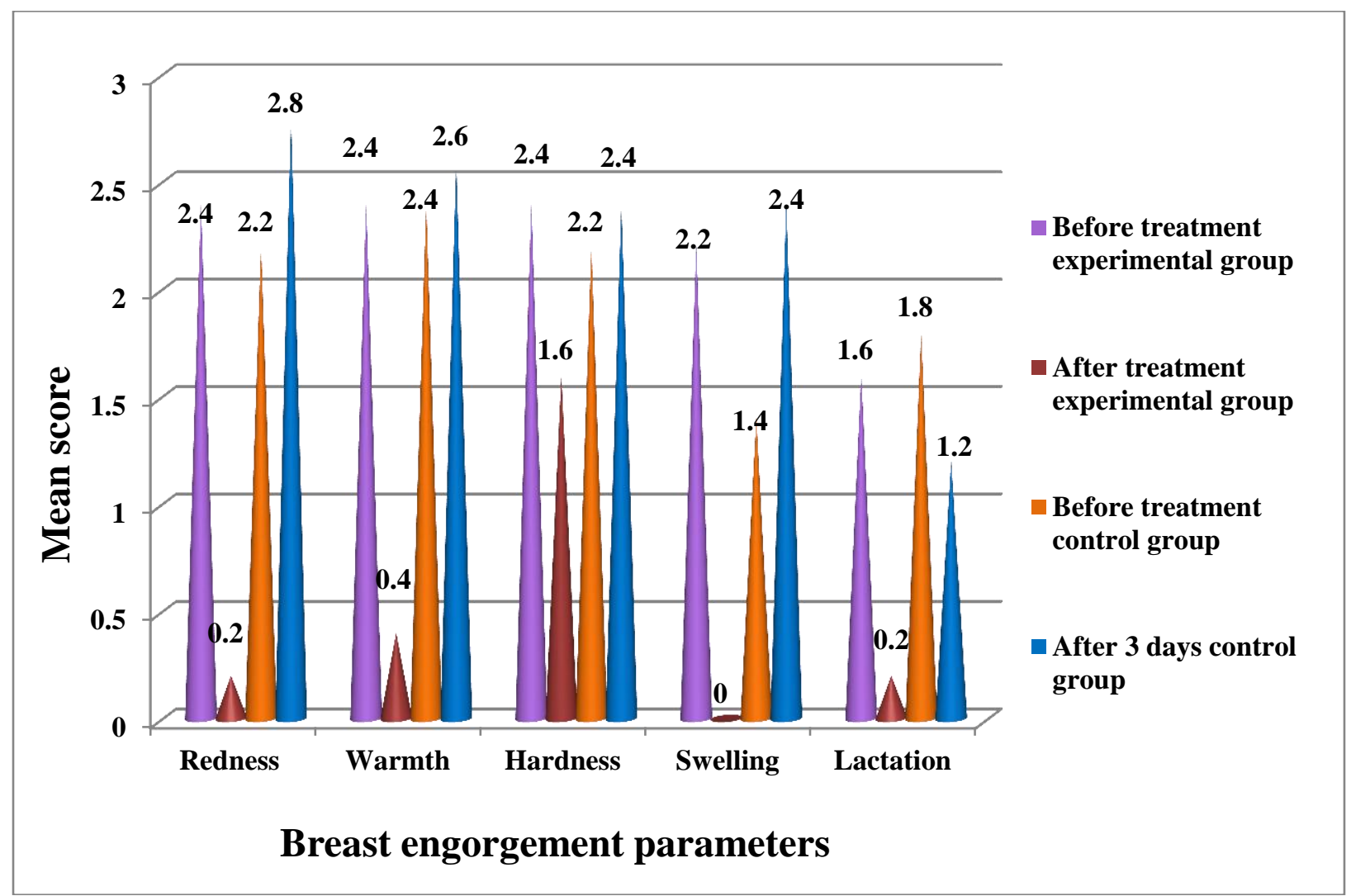

Graph 1:-Mean score of breast engorgement severity rating scale experimental group vs control group 


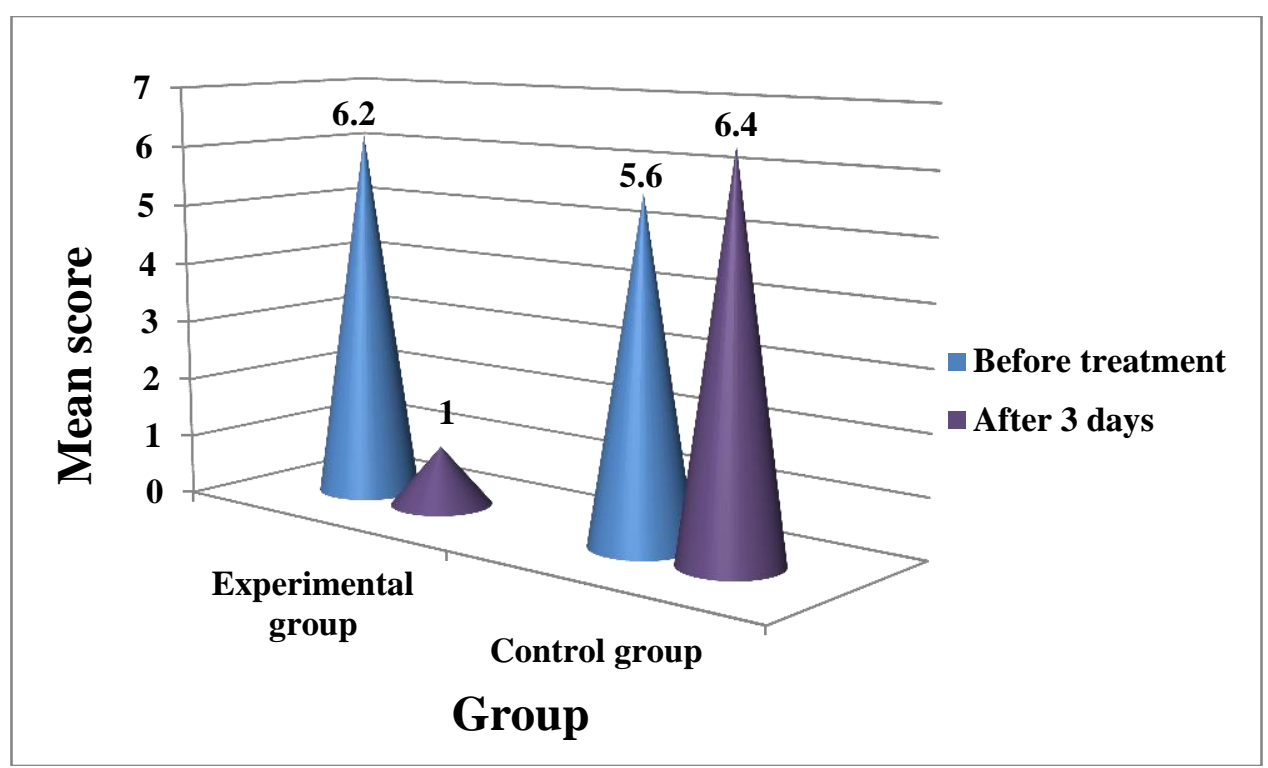

Graph 2:-Mean score of pain in experimental group vs control group

Graph 1 showed the comparison of breast engorgement parameters between experimental group and control group from before to after 3 days which showed that there is significant reduction in all parameters among experimental group then the control group. The graph 2 showed that there was difference between pain score of experimental group and control group from before to after treatment which suggest that there is a huge impact of cabbage leaves on breast engorgement among postnatal women.

\section{Conclusion:-}

The present study conducted only on 10 postnatal women (5 experimental and 5 control) which was given a new light about one of the home-based measure to relieve breast engorgement. Hence, similar study can be perform on larger scale to make it generalized and in determining the impact of chilled cabbage leaves on relieving breast engorgement. The postnatal women and also the people should be aware about the use of such measure which help to relieve the plight of postnatal women caused by engorged breast.

\section{References:-}

1. Census 2011. Gujarat Population Census data 2011.published on 2015. Available from: http://www.census2011.co.in/census/state/gujarat.html

2. Press trust of India. Gujarat maternal mortality rate.2015-16. updated on 19 august 2017. Available from: http://www.ptinews.com/news/8563969-Gujarat-maternal-mortality-rate-rising-since-2014-CAG.html

3. Project Coordinator. District level household and facility survey-3. International Institute for Population Sciences.2007-2008. Available from: http://www.rchiips.org,access. 